\title{
Cannabinoid Transmission in the Prelimbic Cortex Bidirectionally Controls Opiate Reward and Aversion Signaling through Dissociable Kappa Versus $\mu$-Opiate Receptor Dependent Mechanisms
}

\author{
Tasha Ahmad, ${ }^{1}$ Nicole M. Lauzon, ${ }^{1}$ Xavier de Jaeger, ${ }^{1}$ and Steven R. Laviolette ${ }^{1,2,3}$ \\ Departments of ${ }^{1}$ Anatomy and Cell Biology, ${ }^{2}$ Psychiatry, and ${ }^{3}$ Psychology, The Schulich School of Medicine and Dentistry, University of Western Ontario, \\ London, Ontario, Canada N5Y 5T8
}

\begin{abstract}
Cannabinoid, dopamine (DA), and opiate receptor pathways play integrative roles in emotional learning, associative memory, and sensory perception. Modulation of cannabinoid CB1 receptor transmission within the medial prefrontal cortex (mPFC) regulates the emotional valence of both rewarding and aversive experiences. Furthermore, CB1 receptor substrates functionally interact with opiaterelated motivational processing circuits, particularly in the context of reward-related learning and memory. Considerable evidence demonstrates functional interactions between CB1 and DA signaling pathways during the processing of motivationally salient information. However, the role of $\mathrm{mPFC} \mathrm{CB1} \mathrm{receptor} \mathrm{transmission} \mathrm{in} \mathrm{the} \mathrm{modulation} \mathrm{of} \mathrm{behavioral} \mathrm{opiate-reward} \mathrm{processing} \mathrm{is} \mathrm{not} \mathrm{currently}$ known. Using an unbiased conditioned place preference paradigm with rats, we examined the role of intra-mPFC CB1 transmission during opiate reward learning. We report that activation or inhibition of CB1 transmission within the prelimbic cortical (PLC) division of the $\mathrm{mPFC}$ bidirectionally regulates the motivational valence of opiates; whereas $\mathrm{CB} 1$ activation switched morphine reward signaling into an aversive stimulus, blockade of CB1 transmission potentiated the rewarding properties of normally sub-reward threshold conditioning doses of morphine. Both of these effects were dependent upon DA transmission as systemic blockade of DAergic transmission prevented CB1-dependent modulation of morphine reward and aversion behaviors. We further report that CB1-mediated intra-PLC opiate motivational signaling is mediated through a $\mu$-opiate receptor-dependent reward pathway, or a $\kappa$-opiate receptor-dependent aversion pathway, directly within the ventral tegmental area. Our results provide evidence for a novel CB1-mediated motivational valence switching mechanism within the PLC, controlling dissociable subcortical reward and aversion pathways.
\end{abstract}

\section{Introduction}

In the mammalian brain, cannabinoid $\mathrm{CB} 1$ receptor and mesolimbic dopamine (DA) transmission functionally interact with opiate-receptor substrates during the processing of motivationally salient learning and memory (Tanda et al., 1997; Rodríguez De Fonseca et al., 2001). The interconnected ventral tegmental area (VTA) and medial prefrontal cortex (mPFC) contain high levels of $\mathrm{CB} 1$ receptors. $\mathrm{CB} 1$ receptor transmission within these regions can potently modulate rewarding and aversive motivational behaviors and memory formation (Laviolette and Grace, 2006; Zangen et al., 2006; Tan et al., 2010). For example, modulation of CB1 transmission within the prelimbic

Received April 22, 2013; revised Aug. 12, 2013; accepted Aug. 27, 2013.

Author contributions: S.R.L. and T.A. designed research; T.A., N.L., and X.d.J. performed research; S.R.L., T.A., N.L., and X.d.J. analyzed data; T.A. wrote the paper.

This work supported by the Canadian Institutes of Health Research (CIHR MOP- 246144), The Natural Science and Engineering Research Council (NSERC) and an NSERC fellowship to N.M.L.

Correspondence should be addressed to Dr Steven R. Laviolette, Department of Anatomy and Cell Biology, University of Western Ontario, London, 0N, Canada N6A 5C1. E-mail: steven.laviolette@schulich.uwo.ca.

DOI:10.1523/JNEUROSCI.1686-13.2013

Copyright $\odot 2013$ the authors $\quad 0270-6474 / 13 / 3315642-10 \$ 15.00 / 0$ cortical (PLC) division of the mPFC, increases the emotional salience of fear-related stimuli (Laviolette and Grace, 2006; Tan et al., 2010). In addition, considerable evidence demonstrates functional interactions between CB1 transmission and subcortical DAergic signaling. For example, $\Delta$-9-tetrahydrocannabinol (THC) increases glutamate levels within the mPFC and activates downstream DAergic neuronal activity in the mesolimbic pathway (Diana et al., 1998; Pistis et al., 2001, 2002). Furthermore, in vivo extracellular recording studies within the VTA have demonstrated that $\mathrm{CB} 1$ receptor activation increases the spontaneous activity of subcortical DA neuronal populations (French et al., 1997).

Although the euphorigenic effects of opiate-class drugs are well established, similar to many other drugs of abuse, opiates also possess aversive stimulus properties (Bechara and van der Kooy, 1987). The VTA serves as a critical neural region for the processing of opiate-related motivational information (Bozarth and Wise, 1981; Laviolette et al., 2004). Within the VTA, opiaterelated motivational processing is mediated via heterogeneous opiate-receptor populations. Thus, whereas opiates primarily produce rewarding effects via functional interactions with $\mu$-opiate receptor (MOR) substrates (Gysling and Wang, 1983; 

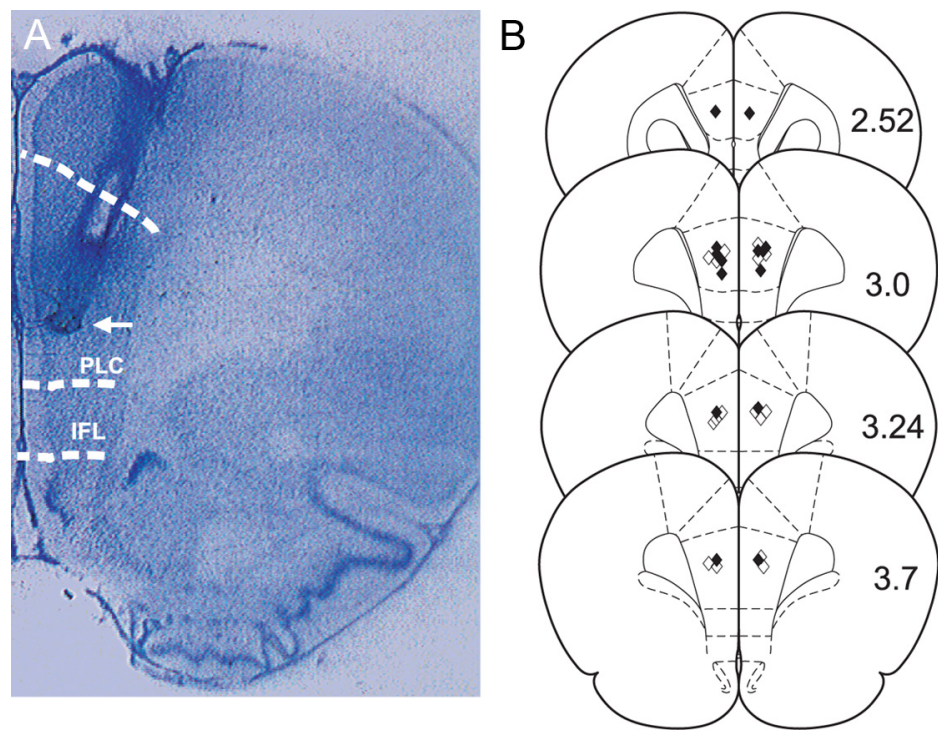

Figure 1. Histological analysis of intra-mPFC microinjection sites. A, Microphotograph of a representative injector placement within the PLC division of the mPFC. B, Schematic representation of select intra-PLC injector locations; $=500 \mathrm{ng}$ WIN 55, 212-2 versus $5 \mathrm{mg} / \mathrm{kg}$ morphine group, $\diamond=500 \mathrm{ng}$ AM 251 versus $0.05 \mathrm{mg} / \mathrm{kg}$ morphine group.

Johnson and North, 1992), activation of $\kappa$-opiate receptor (KOR) subtypes is linked to the aversive stimulus effects of opioids (Bechara and van der Kooy, 1987; Shippenberg and Elmer, 1998; Davis et al., 2009). Anatomically, MOR-sensitive substrates in the VTA predominantly project to the basolateral nucleus of the amygdala (BLA) whereas KOR-sensitive neuronal substrates predominantly project to the nucleus accumbens (NAc; Ford et al., 2006), suggesting a functional segregation within opiatedependent motivational signaling originating from the VTA. Furthermore, efferents from the MPFC to VTA neuronal populations modulate subcortical DA transmission within the mesolimbic pathway, including via direct inputs to DAergic neurons within the VTA (Carr and Sesack, 2000a). Nevertheless, how CB1 transmission within the MPFC may modulate opiate-related motivational information through interactions with subcortical DA substrates is not currently known. Using an unbiased conditioned place preference (CPP) procedure, we examined how pharmacological modulation of CB1 transmission specifically within the PLC division of the MPFC may influence opiaterelated reward learning and memory processing. We report that intra-PLC modulation of CB1 receptor transmission bidirectionally controls the motivational valence of opiate-related behavioral conditioning. Whereas CB1 receptor activation switched the motivational valence of morphine from rewarding to strongly aversive, pharmacological blockade of intra-PLC CB1 receptor transmission strongly increased the reward salience of normally sub-reward threshold conditioning doses of morphine. Furthermore, we demonstrate that intra-PLC CB1 transmission bidirectionally controls opiate motivational valence through dissociable MOR versus KOR-dependent substrates, directly within the VTA.

\section{Materials and Methods}

Animals and surgery. All experimental procedures were performed in accordance with Institutional, Federal, and Provincial Animal Care guidelines. Adult male Sprague Dawley rats (350-400 g; Charles River Canada) were anesthetized with an intraperitoneal injection of a ketamine $(80 \mathrm{mg} / \mathrm{ml})$-xylazine $(6 \mathrm{mg} / \mathrm{kg})$ mixture, and placed in a stereotaxic device. For intra-PLC microinfusions, two stainless steel guide cannulae (22 gauge) were implanted into the PLC division of the mPFC using the following coordinates $\left(15^{\circ}\right.$ angle): from bregma, anteroposterior (AP) $+2.9 \mathrm{~mm}$, lateral (LAT) $\pm 1.9 \mathrm{~mm}$, ventral $(\mathrm{V})-3.0 \mathrm{~mm}$ from the dural surface (Laviolette and Grace, 2006). For experiments involving intra-PLC and intra-VTA microinfusions, rats received two additional cannulae implanted in the VTA using the following coordinates $\left(10^{\circ}\right.$ angle $)$ : from bregma, AP $-5.0 \mathrm{~mm}$, LAT $\pm 2.3 \mathrm{~mm}$, and $\mathrm{V}-8.0 \mathrm{~mm}$ from the dural surface. Dental acrylic and jeweler's screws were used to secure the cannulae to the skull surface.

Drug treatments. The highly selective CB1 agonist (WIN 55,212-2; Tocris Bioscience) or antagonist (AM251; Tocris Bioscience) were first dissolved in dimethyl sulfoxide then diluted in physiological saline ( $\mathrm{pH}, 7.4)$. Bilateral microinfusions were performed over a period of $1 \mathrm{~min}$ via plastic tubing connected to a $1 \mu \mathrm{l}$ Hamilton microsyringe. All microinfusions consisted of a total volume of $0.5 \mu \mathrm{l}$. Injectors were left in place for an additional $1 \mathrm{~min}$ to ensure adequate diffusion of the drug from the injector tip. The $\mu$-opioid receptor antagonist cyprodime hydrochloride (Tocris Bioscience) and $\kappa$-opioid receptor antagonist norbinaltorphimine dihydrochloride (Tocris Bioscience) were dissolved in physiological saline, $\mathrm{pH}$ 7.4, and microinfused bilaterally intra-VTA (50 and $500 \mathrm{ng} / 0.5 \mu \mathrm{l}$ ). Morphine sulfate (Macfarland-Smith) and the broad-spectrum DA receptor antagonist $\alpha$-flupenthixol hydrochloride ( $\alpha$-flu; Tocris Bioscience) were dissolved in physiological saline. For all experiments involving a pharmacological pretreatment, rats received pretreatments before both saline and morphine conditioning trials. This built-in experimental control mechanism controls for any confounds from potential motivational effects of pretreatment drugs. For CPP conditioning, two doses of morphine were used: a supra-reward threshold dose $(5.0 \mathrm{mg} / \mathrm{kg}$, i.p. $)$ which produces robust CPP, and a sub-reward threshold dose $(0.05 \mathrm{mg} / \mathrm{kg}$, i.p. $)$ which normally fails to produce a significant CPP (Bishop et al., 2011; Lintas et al., 2012). Systemic morphine was administered immediately after intracranial micro-infusions. For DA antagonist treatment, animals received $0.8 \mathrm{mg} / \mathrm{kg}$ i.p. of $\alpha$-flu $2.5 \mathrm{~h}$ before conditioning. This dose and time course of $\alpha$-flu produces no motivational effects in and of itself.

Place conditioning procedure. An unbiased, fully counterbalanced CPP procedure was used, as described previously (Bishop et al., 2011; Lintas et al., 2012). Briefly, saline or morphine (systemic or intra-VTA) was paired with one of two environments which differed in terms of color, texture, and smell. Following recovery from surgery, rats were randomly assigned to an experimental group. All rats were exposed to a preconditioning phase where they were placed into a motivationally neutral gray box for $20 \mathrm{~min}$. The following day, the $8 \mathrm{~d}$ conditioning phase was commenced. One conditioning environment was white with a wire-mesh floor covered in woodchips. The alternate environment was black with a smooth Plexiglas floor wiped down with $2 \%$ acetic acid immediately before the animal was placed into it. Experimental treatments were counterbalanced such that each animal was randomly assigned to receive morphine in either the white or the black environment and vice versa when receiving saline. As previously reported, rats displayed no baseline preference for either of these environments. During conditioning, rats receive an equal number of morphine-environment versus saline-environment pairings. Therefore, over the $8 \mathrm{~d}$ procedure rats receive four $30 \mathrm{~min}$ morphine-environment pairings and four $30 \mathrm{~min}$ saline-environment pairings. During testing, rats are placed on a narrow gray zone separating the two test environments and times spent in each environment are digitally recorded and scored separately for each animal over a $10 \mathrm{~min}$ test session. All rats are tested in a drug free state.

Histology. After completion of experiments, rats were anesthetized with an overdose of euthanyl (sodium pentobarbitol; $240 \mathrm{mg} / \mathrm{kg}$, i.p.) and perfused with isotonic saline followed by $10 \%$ formalin. Brains were 
extracted, sliced at $40 \mu \mathrm{m}$, and stained with Cresyl Violet to allow for histological analysis of injection sites. Injector placements were confirmed using light microscopy, and rats with misplaced guide cannulae were excluded from analysis.

Data analysis. Data were analyzed with either a two-way ANOVA or Student's $t$ tests where appropriate. Post hoc analyses were performed with Newman-Keuls and Fisher's least significant difference test.

\section{Results}

\section{Intra-mPFC and VTA}

histological analysis

Histological analysis indicated microinfusion injector cannula placements to be bilaterally localized within the anatomical boundaries of the MPFC and VTA region, as determined by the Atlas of Paxinos and Watson (1986). In Figure $1 A$, we present a microphotograph showing a representative injector placement within the PLC division of the mPFC. In Figure $1 B$, we present a schematic illustration showing representative intra-mPFC bilateral cannulae placements along the rostral-caudal axis of the mPFC. Rats found to have cannulae placements outside the anatomical boundaries of the mPFC or VTA were excluded from analysis. A total of three rats with misplaced VTA cannulae were excluded from the experimental analyses.

\section{Intra-PLC $\mathrm{CB} 1$ receptor activation} switches the motivational effects of morphine from rewarding to aversive We performed bilateral intra-PLC microinfusions of the CB1 agonist WIN $55,212-2$ ( 50 or $500 \mathrm{ng} / 0.5 \mu \mathrm{l}$ ), before either sub- or supra-reward threshold morphine CPP conditioning. These doses of intra-cranial WIN 55,212-2 are pharmacologically specific and can be blocked by coadministration of selective CB1 antagonists (Laviolette and Grace, 2006; Tan et al., 2011). First, challenging the motivational effects of a sub-threshold conditioning dose of morphine $(0.05 \mathrm{mg} / \mathrm{kg}$, i.p. $)$, two-way ANOVA revealed a significant interaction between group and treatment $\left(F_{(2,43)}=\right.$ 38.6; $p<0.001)$ on times spent in either saline or morphine paired environments during CPP testing. Post hoc analysis revealed that whereas rats receiving a higher dose of WIN 55,212-2 $(500 \mathrm{ng} / 0.5 \mu \mathrm{l})$ demonstrated a significant aversion to morphinepaired environments $(n=8, p<0.01)$, this effect was absent in rats receiving a lower dose of WIN 55,212-2 (50 ng/0.5 $\mu \mathrm{l} ; n=7)$, or vehicle $(n=7)$ with rats spending equal times in both environments $(p>0.05$; Fig. $2 A)$. Based upon this dose-dependent effect, we chose the highest behaviorally effective dose of 500 $\mathrm{ng} / 0.5 \mu \mathrm{l}$ of WIN 55,212-2 for subsequent behavioral experiments. In our next series of experiments, we microinfused WIN 55,212-2 (500 ng) and challenged a suprathreshold conditioning dose of morphine $(5.0 \mathrm{mg} / \mathrm{kg}$, i.p.). Two-way ANOVA revealed a significant interaction between group and treatment $\left(F_{(1,31)}=\right.$ 673.7; $p<0.001)$. Post hoc analysis revealed a highly significant
SUB-REWARD THRESHOLD MORPHINE (0.05 mg/kg; i.p.)

A

vironment

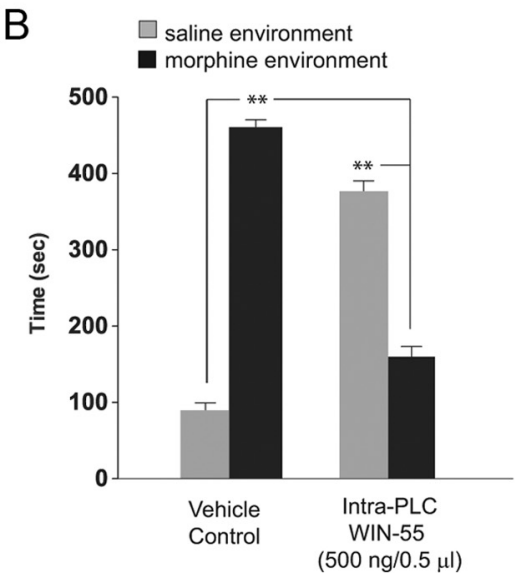

C

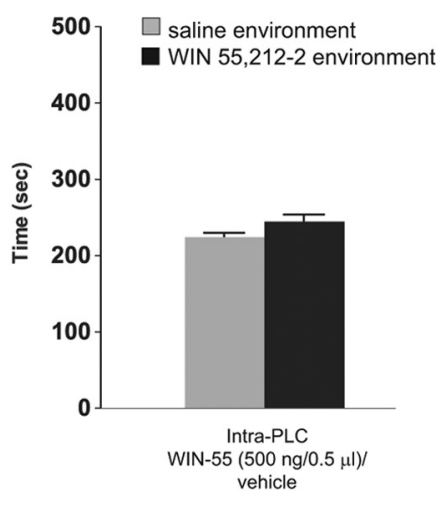

Figure 2. Effects of intra-PLC CB1 receptor activation on morphine CPP conditioning. A, Bilateral intra-PLC micro-infusions of the (B1 receptor agonist WIN 55,212-2 (50 and $500 \mathrm{ng} / 0.5 \mu \mathrm{l})$, dose-dependently produced a morphine aversion against a sub-reward threshold conditioning dose of morphine $(0.05 \mathrm{mg} / \mathrm{kg}$, i.p.). Both vehicle controls and rats receiving a lower dose of 列 . $\mathrm{mg} / \mathrm{kg}$. . similarly switches the rewarding properties of morphine into aversion, with rats demonstrating robust (PA for morphine-paired environments. $C$, In control rats receiving intra-PLC WIN 55,212-2 (500 ng/ $0.5 \mu \mathrm{l} ; n=8)$ versus vehicle, no preference for either environment is observed. ${ }^{*} p<0.05{ }^{* *} p<0.01$, for this and all subsequent figures.

aversion to morphine-paired environments at testing in rats receiving intra-PLC WIN 55,212-2 $(n=8, p<0.01$; Fig. $2 B)$. Furthermore, comparing times spent in morphine-paired environments across groups, revealed that rats receiving intra-PLC WIN 55, 212-2 spent significantly less time in morphine-paired environments relative to vehicle controls $(n=7 ; p<0.01)$. Thus, whereas intra-PLC CB1 receptor activation produced no motivational effects in and of itself, activation of CB1 transmission potently and dose-dependently switched the motivational valence of both sub- and supra-reward threshold doses of morphine into robust aversive behavioral responses. To control for any potential behavioral effects of intra-PLC WIN 55,212-2, we ran a subsequent control group $(n=8)$ in which rats received either the previously established effective dose of WIN 55,212-2 (500 ng/0.5 $\mu l)$ in one environment, or vehicle microinfusions in the control environment. Statistical analysis revealed that intra-PLC WIN $55,212-2$ produced no motivational effects, with rats demonstrating neither preference nor aversion for WIN 55,212-2-paired environments $\left(t_{(7)}=2.1, p>0.05\right.$; Fig. $\left.2 C\right)$. 
SUB-REWARD THRESHOLD

MORPHINE (0.05 mg/kg; i.p.)

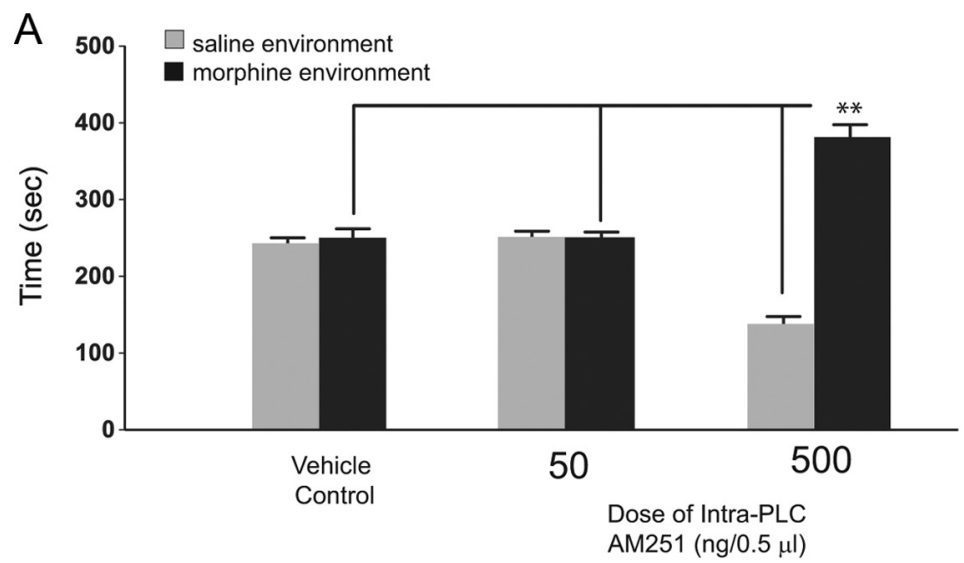

SUPRA-REWARD THRESHOLD

MORPHINE (5 mg/kg; i.p.)
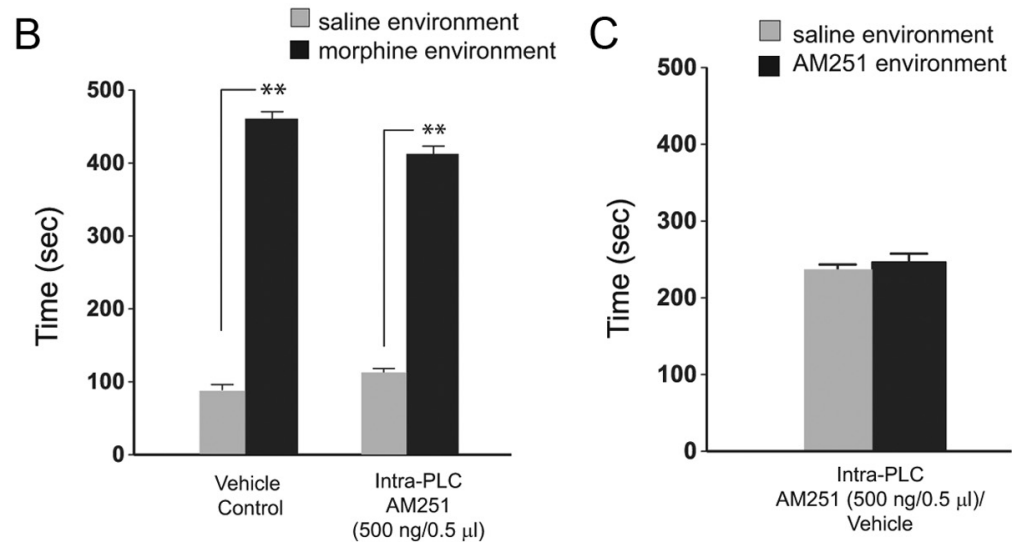

Figure 3. Effects of intra-PLCCB1 receptor blockade on morphine CPP conditioning. $A$, Bilateral intra-PLC microinfusions of the CB1 receptor antagonist, AM251 (50 ng/0.5 $\mu \mathrm{l} ; n=8$, or $500 \mathrm{ng} / 0.5 \mu \mathrm{l} ; n=7$ ) dose-dependently potentiated the rewarding effects of morphine relative to vehicle controls that displayed no significant preference for either environment. $\boldsymbol{B}$, Conversely, bilateral intra-PLC microinfusions of AM251 ( $500 \mathrm{ng} / 0.5 \mu \mathrm{l})$ versus a supra-reward threshold dose of morphine $(5.0 \mathrm{mg} / \mathrm{kg}$, i.p) has no effect on morphine reward conditioning, with both drug $(n=8)$ and vehicle control $(n=8)$ groups demonstrating robust morphine environment CPP. C, In control rats receiving intra-PLC AM251 (500 ng $/ 0.5 \mu \mathrm{l} ; n=8)$ versus vehicle, no preference for either environment is observed.

\section{Intra-PLC CB1 receptor blockade potentiates the rewarding properties of morphine}

We next examined the potential effects of intra-PLC CB1 receptor blockade on the motivational behavioral effects of either sub or supra-reward threshold conditioning doses of morphine with the selective CB1 antagonist, AM251 (50-500 ng/0.5 $\mu \mathrm{l}$ ). First, challenging the behavioral effects of a sub-reward threshold conditioning dose of morphine $(0.05 \mathrm{mg} / \mathrm{kg}$, i.p. $)$, we administered either 50 or $500 \mathrm{ng} / 0.5 \mu \mathrm{l}$ directly into the PLC. Two-way ANOVA demonstrated a significant interaction between group and treatment $\left(F_{(2,43)}=76.2 ; p<0.001\right)$ on times spent in either saline or morphine paired environments. Post hoc analysis revealed that animals receiving intra-PLC micro-infusions of AM251 (500 $\mathrm{ng} / 0.5 \mu \mathrm{l}, n=8, p<0.001)$ spent significantly more time in morphine-paired environments (Fig. 3A). However, for the vehicle control group $(n=8)$ and rats receiving a lower dose of AM 251 (50 ng/0.5 $\mu \mathrm{l}, n=7$ ), no CPP was observed. Furthermore, comparing times spent in morphine-paired environments across groups revealed that rats receiving intra-PLC AM251 (500 ng/0.5 $\mu l)$ spent significantly greater times in morphine-paired environ- ments, relative to controls $(p<0.01)$. Based upon this initial dose-response analysis, we chose the highest behaviorally effective dose of $500 \mathrm{ng} / 0.5 \mu \mathrm{l}$ of AM251 for subsequent behavioral experiments. We next examined the potential effects of intra-PLC AM251 (500 ng/0.5 $\mu$ l) against a supra-reward threshold conditioning dose of morphine $(5 \mathrm{mg} / \mathrm{kg}$, i.p.). Twoway ANOVA demonstrated a significant interaction $\left.F_{(1,31)}=15.8 ; p=0.0005\right)$ between group and treatment, with rats receiving either intra-PLC vehicle or AM251 demonstrating significant CPP for morphine-paired environments $(n=$ $8, p<0.01 ; n=8, p<0.01$ respectively; Fig. $3 B$ ). To control for any potential behavioral effects of intra-PLC AM251, we ran a subsequent control group $(n=8)$ in which rats received either the previously established effective dose of AM251 (500 $\mathrm{ng} / 0.5 \mu \mathrm{l}$ ) in one environment, or vehicle microinfusions in the control environment. Statistical analysis revealed that intra-PLC AM251 produced no motivational effects, with rats demonstrating neither preference nor aversion for AM251-paired environments $\left(t_{(7)}=0.89\right.$, $p>0.05$; Fig. $3 C$ ). Thus, whereas intraPLC CB1 receptor blockade produced no motivational effects in and of itself, blockade of CB1 transmission potently and dose-dependently potentiated the rewarding properties of a normally subreward threshold conditioning dose of morphine, while having no effect on the rewarding properties of a supra-reward threshold dose of morphine.

In Figure 4, we present a summary of the behavioral conditioning effects of intra-PLC CB1 receptor blockade (AM 251) or activation (WIN 55,212-2) on the motivational properties of morphine, showing average difference scores (times in drug minus salinepaired environments), comparing sub-reward threshold morphine effects (Fig. $4 A$ ) or supra-reward threshold morphine effects (Fig. 4B).

\section{CB1 receptor modulation of opiate reward learning} is dopamine-dependent

Given our findings that intra-PLC CB1 receptor transmission modulates opiate reward and aversion signals (Figs. 2, 3), we next examined the potential functional interactions between intraPLC CB1 receptor modulation and DAergic transmission. Accordingly, we challenged both the morphine reward-potentiating and aversion-inducing effects of intra-PLC CB1 receptor modulation by pretreating rats with the broad-spectrum DA receptor antagonist ( $\alpha$-flupenthixol), using a systemic dose $(0.8 \mathrm{mg} / \mathrm{kg}$, i.p.) which has been shown previously to block the rewarding properties of opiates in the opiate-dependent/withdrawn state (Laviolette et al., 2004). First, we challenged the ability of intraPLC WIN 55, 212-2 (500 ng/0.5 ml) to induce morphine place aversions, with $\alpha$-flu pretreatment (see Materials and Methods) 
versus supra-reward threshold conditioning dose of morphine (5 $\mathrm{mg} / \mathrm{kg}$, i.p.). Two-way ANOVA revealed a significant interaction between treatment and group $\left(F_{(1,29)}=81.33 ; p<0.001\right)$. Post hoc analysis revealed that rats treated with intra-PLC vehicle demonstrated a robust morphine $\operatorname{CPP}(n=8 ; p<0.01)$, whereas, consistent with our previous results (Fig. 2), rats treated with intra-PLC WIN 55,212-2 $(n=7)$ demonstrated a strong morphine environment aversion $(p<0.01$; Fig. $5 A)$. However, in rats pretreated with $\alpha$-flu $(n=7)$, the ability of intra-PLC CB1 receptor activation to induce a morphine place aversion was completely blocked, with rats showing no preference or aversion for either environment at testing ( $p<0.05$; Fig. $5 A)$.

Next, we challenged the ability of intra-PLC AM251 (500 ng/ $0.5 \mathrm{ml}$ ) to potentiate the rewarding effects of a sub-reward conditioning dose of morphine $(0.05 \mathrm{mg} / \mathrm{kg}$, i.p. $)$, with $\alpha$-flu pretreatment. Two-way ANOVA revealed a significant interaction between treatment and group $\left(F_{(1,27)}=257.25 ; p<0.001\right)$. Post hoc analysis revealed that rats treated with intra-PLC vehicle demonstrated no preference for environments paired with subreward threshold morphine $(n=8 ; p>05)$. In contrast, consistent with our previous results (Fig. 2), rats treated with intra-PLC AM251 $(n=7)$ demonstrated a strong morphine place preference $(p<0.01$; Fig. $5 B)$. However, in rats pretreated with $\alpha$-flu $(n=8)$, the ability of intra-PLC CB1 receptor blockade to potentiate the rewarding properties of morphine were completely blocked, with rats showing neither preference nor aversion for either environment at testing $(p<0.05$; Fig. $5 B)$.

\section{Intra-PLC CB1-mediated morphine aversions are mediated through $\kappa$-opiate receptor transmission in the VTA}

Given the well established role of $\kappa$-opiate receptor transmission within the VTA in the mediation of opiate-related aversion (zharv;27Margolis et al., 2003), we next tested whether the ability of intra-PLC CB1 activation to induce morphine-related place aversion was dependent upon a KOR substrate directly within the VTA. Thus, we challenged the aversion-inducing effects of intraPLC WIN 55,212-2 (500 ng/0.5 $\mu \mathrm{l}$ ) with the highly selective KOR antagonist nor-binaltorphimine dehydrochloride (nor-BNI) by microinfusing nor-BNI into the VTA $(50-500 \mathrm{ng} / 0.5 \mu \mathrm{l})$ before intra-PLC CB1 receptor activation (see Materials and Methods), using a supra-reward threshold conditioning dose of morphine (5 mg/kg, i.p.). Two-way ANOVA revealed a significant interaction $\left(F_{(1,27)}=41 ; p<0.001\right)$ between group and treatment. Post hoc analysis revealed that for rats receiving a lower dose of intraVTA nor-BNI (50 ng/0.5 $\mu \mathrm{l} ; n=8$ ), a morphine environment aversion was present $(p<0.05)$, similar, although slightly attenuated, relative to controls receiving only intra-PLC WIN 55,212-2 $(n=8 ; p<0.01$; Fig. $6 A)$. In contrast, for rats receiving a higher dose of intra-VTA nor-BNI, morphine environment aversions were completely blocked, and rats displayed a robust morphine CPP $(n=6, p<0.01)$. Thus, blockade of KOR signaling in the VTA dose-dependently reversed the ability of intraPLC WIN 55, 212-2 to induce morphine environment aversions, and revealed the rewarding behavioral effects of a supra-reward threshold conditioning dose of morphine (Fig. 6A). To determine the specificity of the intra-VTA KOR mediated effect, we ran an additional control group receiving intra-PLC WIN 55,212-2 with intra-VTA cyprodime hydrochloride, a highly competitive MOR antagonist $(n=6)$. This group displayed a robust morphine-environment aversion, consistent with previous results (Fig. 2) demonstrating that intra-VTA MOR transmission is not involved in the aversion-inducing effects of intraPLC CB1 receptor activation $\left(t_{(6)}=14.9 ; p<0.01\right.$; Fig. $6 A$, right $)$.
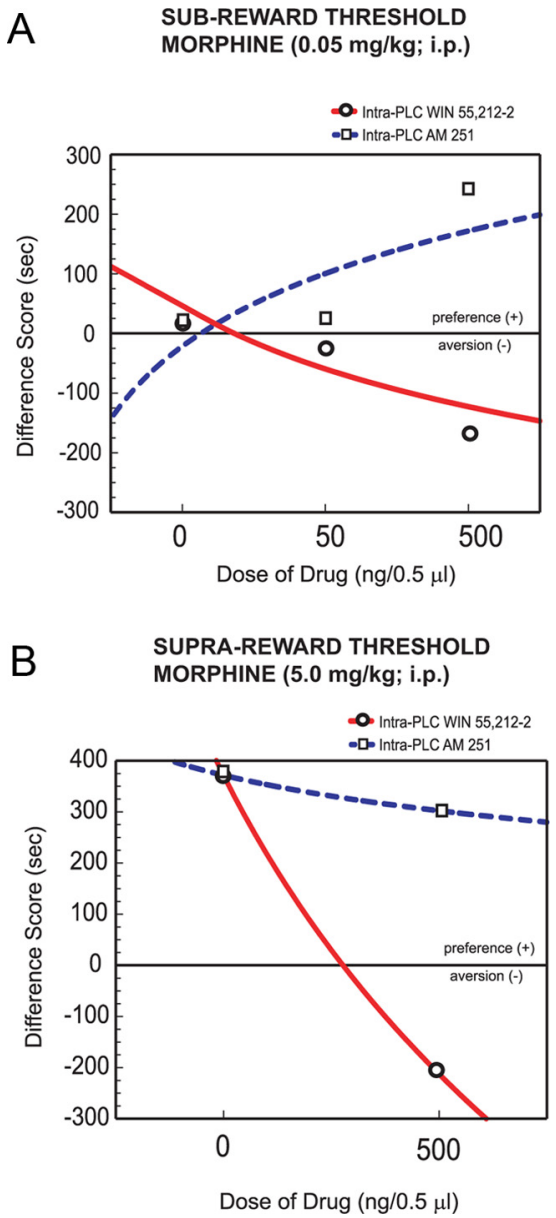

Figure 4. Behavioral effects of intra-PLC CB1 receptor activation or blockade on morphine place conditioning. $\boldsymbol{A}$, Summary of the bidirectional behavioral effects of intra-PLC AM-251 (50-500 ng/0.5 $\mu$ l) or WIN 55,212-2 (50-500 ng/0.5 $\mu$ l) on sub-threshold morphine (0.05 $\mathrm{mg} / \mathrm{kg}$, i.p.) reward or aversion effects, presented as difference scores (time in drug minus saline-paired environments). $\boldsymbol{B}$, Summary of the effects of intra-PLC AM $251(500 \mathrm{ng} / 0.5 \mu \mathrm{l})$ or WIN $55212-2(500 \mathrm{ng} / 0.5 \mu \mathrm{l})$ on supra-reward threshold $(5.0 \mathrm{mg} / \mathrm{kg}$, i.p.) morphine.

To control for any potential motivational effects of intra-VTA nor-BNI alone, an additional control group $(n=8)$ received bilateral intra-VTA cannulations and received the highest behaviorally effective dose of intra-VTA nor-BNI ( $500 \mathrm{ng} / 0.5 \mu \mathrm{l})$ in one conditioning environment, and intra-VTA vehicle in the alternate environment. Analysis of CPP behavior revealed that intraVTA nor-BNI produced no motivational effects in and of itself as rats did not demonstrate any significant difference in times spent in either conditioning environment (Fig. $6 \mathrm{~A}$, right; $t_{(7)}=1.1814$, $p>0.05)$.

\section{Intra-PLC CB1-mediated morphine reward potentiation is} mediated through $\boldsymbol{\mu}$-opiate receptor transmission in the VTA We next tested whether the ability of intra-PLC CB1 blockade to potentiate the rewarding effects of morphine were dependent upon a MOR substrate directly within the VTA. Thus, we challenged the reward-potentiating effects of intra-PLC AM251 (500 $\mathrm{ng} / 0.5 \mu \mathrm{l}$ ) with the highly selective MOR antagonist cyprodime hydrochloride, by directly microinfusing cyprodime into the VTA (50-500 ng/0.5 $\mu \mathrm{l}$ ) before intra-PLC CB1 receptor blockade (see Materials and Methods), using a sub-reward conditioning dose of morphine $(0.05 \mathrm{mg} / \mathrm{kg}$; i.p.). Two-way ANOVA revealed a significant interaction $\left(F_{(1,27)}=72.7 ; p<0.001\right)$ between group 

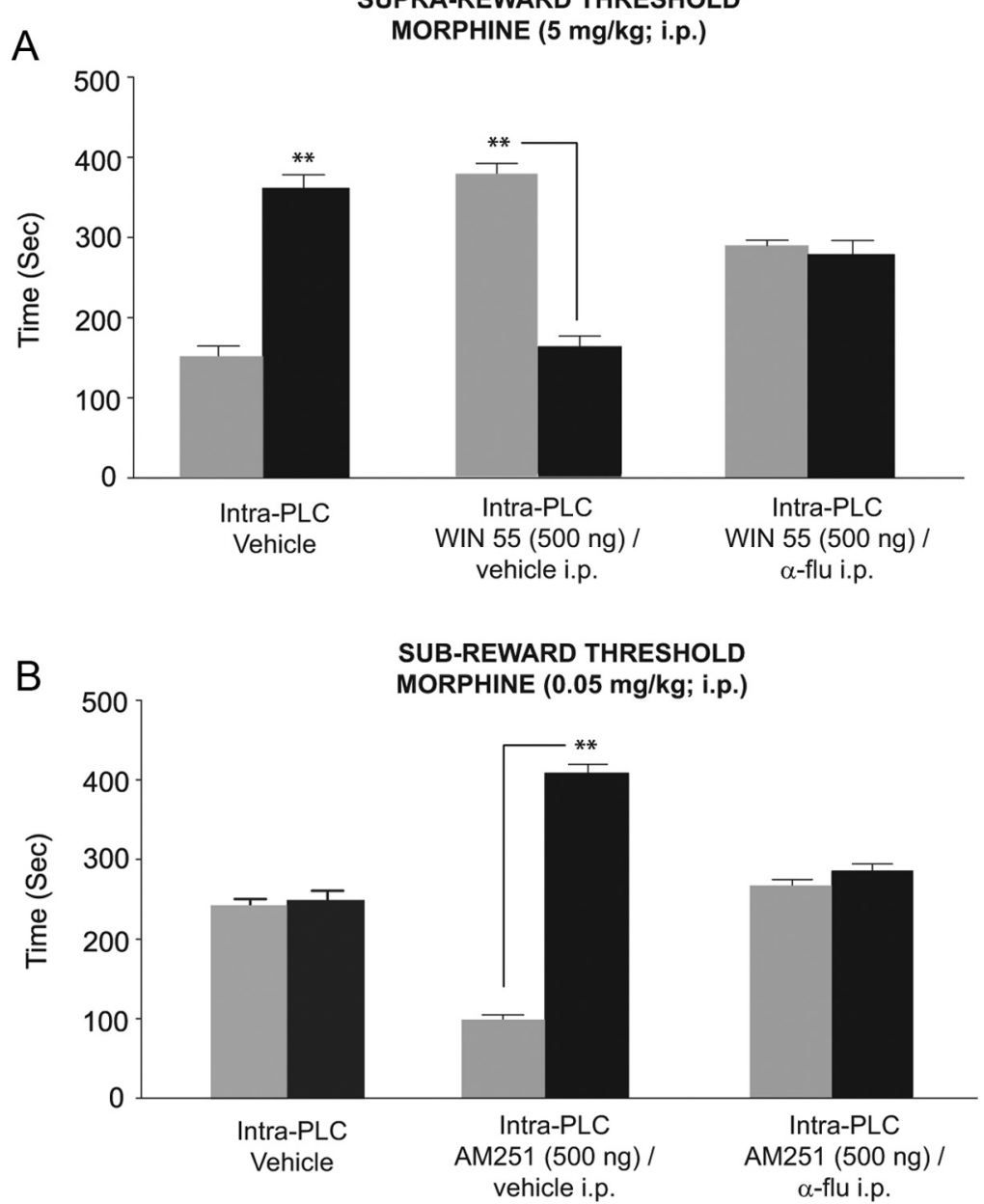

Figure 5. Effects of DA receptor blockade on intra-PLC mediated modulation of opiate motivational processing. $\boldsymbol{A}$, Rats treated with intra-PLC vehicle demonstrate robust CPP for environments paired with supra-reward threshold morphine $(n=8)$. Relative to vehicle pretreated controls $(n=8)$, pretreatment with the broad-spectrum DA receptor antagonist $\alpha$-flu $(0.8 \mathrm{mg} / \mathrm{kg}$, i.p.) blocked the ability of intra-PLC WIN $55,212-2(500 \mathrm{ng} / 0.5 \mu \mathrm{l} ; n=7)$ to induce a behavioral morphine aversion to a supra-reward threshold conditioning dose of morphine $(5.0 \mathrm{mg} / \mathrm{kg}$, i.p.). $\boldsymbol{B}$, Rats treated with intra-PLC vehicle demonstrated no preference for environments paired with sub-reward threshold morphine $(n=8)$. In contrast, rats treated with intra-PLC AM251 $(n=7)$ demonstrated a strong morphine CPP $(p<0.01 ; \boldsymbol{B})$. However, in rats pretreated with $\alpha$-flu $(n=8)$, the ability of intra-PLC CB1 receptor blockade to potentiate the rewarding properties of morphine is blocked.

and treatment. Post hoc analysis revealed that for rats receiving a lower dose of cyprodime ( $50 \mathrm{ng} / 0.5 \mu \mathrm{l})$, intra-PLC AM251 was able to potentiate the rewarding properties of sub-reward threshold morphine, with these rats demonstrating a significant morphine CPP $(n=7, p<0.05$; Fig. $6 B)$. However, in rats receiving a higher dose of intra-VTA cyprodime $(500 \mathrm{ng} / 0.5 \mu \mathrm{l})$, the morphine reward potentiating effects of intra-PLC AM251 were completely blocked, with rats showing no preference for morphine-paired environments $(n=7 ; p>0.05$; Fig. $6 B)$. Thus, intra-VTA cyprodime dose-dependently reverses the behavioral effects of intra-PLC CB1 receptor blockade on morphine reward processing. To determine the specificity of the intra-VTA MORmediated effect, we ran an additional control group $(n=6)$ receiving intra-PLC AM251 (500 ng/0.5 $\mu \mathrm{l}$ ) with our previously established effective dose of intra-VTA nor-BNI $(500 \mathrm{ng} / 0.5 \mu \mathrm{l})$. These rats displayed a potentiated morphine reward behavioral response $\left(t_{(5)}=\right.$ $8.74 ; p<0.01$ ), consistent with previous results (Fig. 3), demonstrating that intra-VTA KOR transmission is not involved in the reward potentiating effects of intra-PLC CB1 receptor blockade. To control for any potential motivational effects of intra-VTA cyprodime alone, an additional control group $(n=8)$ received bilateral intra-VTA cannulations and received the highest behaviorally effective dose of intra-VTA cyprodime $(500 \mathrm{ng} / 0.5$ $\mu \mathrm{l})$ in one conditioning environment, and intra-VTA vehicle in the alternate environment. Analysis of CPP behavior revealed that intra-VTA nor-BNI produced no motivational effects in and of itself as rats did not demonstrate any significant difference in times spent in either conditioning environment (Fig. $6 B$, right; $t_{(7)}=0.7281, p>0.05$ ). Histological analysis of intra-VTA microinfusion locations revealed injection sites to be within the anatomical boundaries of the VTA as defined by Paxinos and Watson (2006). In Figure 7A, we present a microphotograph showing a typical bilateral intra-VTA cannulae placement. In Figure $7 B$, we present a schematic summary of intra-VTA microinjection locations. Postexperimental histological analysis revealed that effective intra-VTA doses of nor-BNI (500 ng/0.5 $\mu \mathrm{l}$ ) were predominantly localized to the anterior VTA (Fig. 7C). Postexperimental histological analysis revealed that effective intra-VTA doses of cyprodime $(500 \mathrm{mg} / 0.5 \mu \mathrm{l})$ were predominantly localized to the posterior VTA (Fig. 7C).

\section{Discussion}

We report that $\mathrm{CB} 1$ transmission within the PLC division of the mPFC, bidirectionally modulates the motivational behavioral effects of systemic opiates. Although activation of CB1 transmission switched a normally rewarding behavioral effect of morphine into aversion, blockade of CB1 transmission potentiated the rewarding properties of normally subreward threshold conditioning doses of morphine. This CB1-mediated switching mechanism was functionally dissociable, DA-dependent, and mediated through either a MOR-dependent reward substrate, or a KOR-dependent aversion signaling substrate, directly within the VTA.

\section{Bidirectional control of opiate reward and aversion signals} through CB1 receptor transmission in prelimbic cortex

Considerable evidence indicates functional interactions between opiate, cannabinoid, and DAergic transmission during the processing of motivationally salient information (Cheer et al., 2004; Sperlágh et al., 2009; Akirav and Fattore, 2011). Specifically, within the mPFC-VTA circuit, CB1 receptor transmission modulates downstream DAergic activity within the VTA. In terms of functional interactions between the MPFC and VTA, the mPFC sends descending projections to neuronal subpopulations within the VTA, including both DAergic and non-DAergic neurons (Carr and Sesack, 2000a,b; Sesack and Carr, 2002). Interestingly, $\mathrm{CB} 1$ agonists have been reported to increase the spontaneous activity of mPFC neuronal populations and attenuate the inhibitory effects of VTA DAergic stimulation on mPFC neuronal activity, suggesting that systemic cannabinoid activation may 

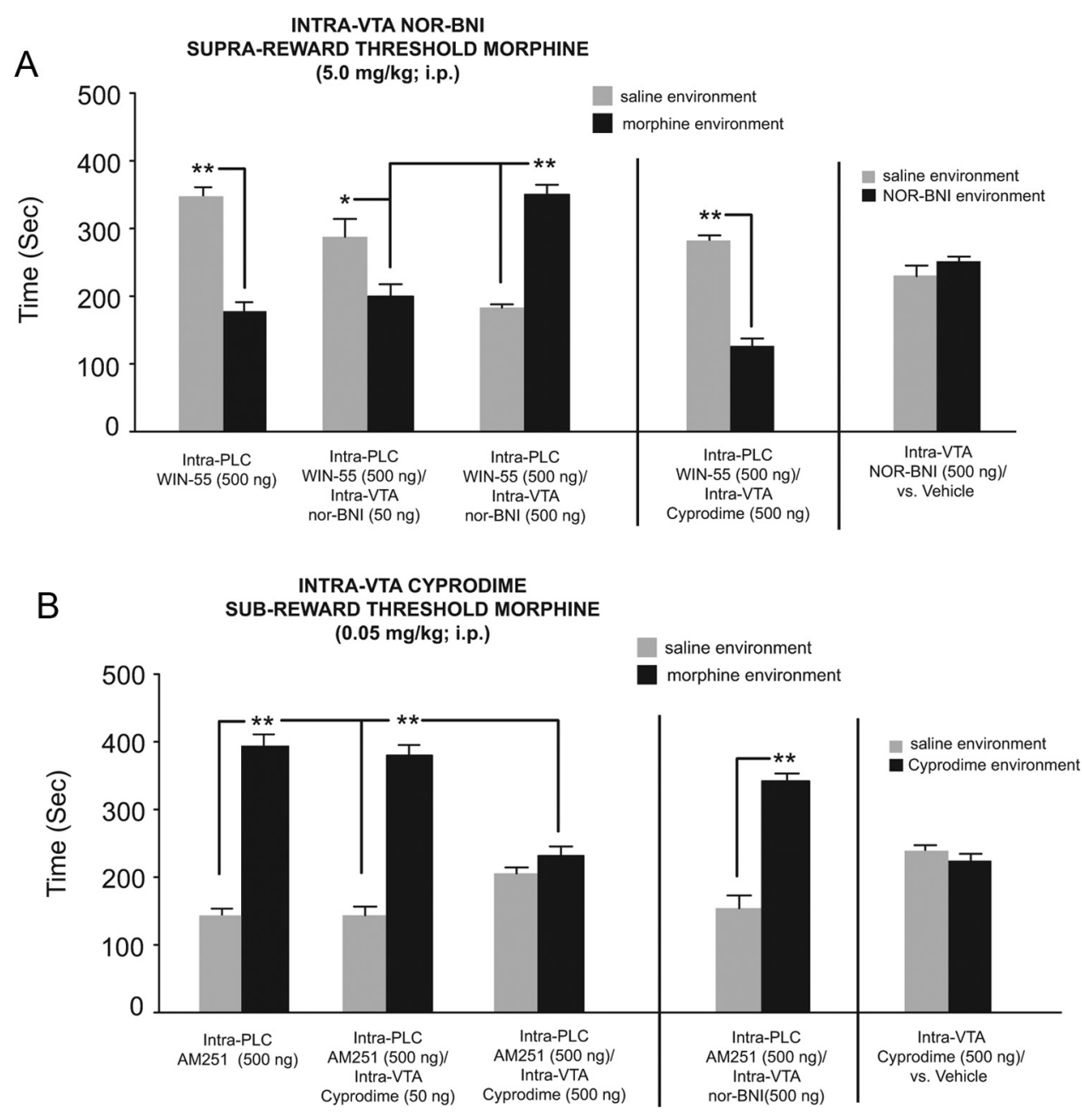

Figure 6. Effects of intra-VTA $\kappa$ - or $\mu$-opiate receptor blockade on CB1 receptor-mediated modulation of opiate reward and aversion behaviors. $A$, Relative to rats receiving intra-PLC WIN $55,212-2(500 \mathrm{ng} / 0.5 \mathrm{ml})$ versus supra-reward threshold morphine $(n=8)$, intra-PLC administration of WIN 55,212-2 (500 ng/0.5 $\mu$ l) following intra-VTA administration of the KOR antagonist nor-BNI [50 ( $n=8)$ or $500(n=6) \mathrm{ng} / 0.5 \mu$ l] dose-dependently blocks the ability of intra-PLC CB1 activation to switch morphine reward signaling into aversion. However, intra-VTA administration of a MOR antagonist, cyprodime ( $500 \mathrm{ng} / 0.5 \mu \mathrm{l} ; n=6)$ fails to reverse the effects of intra-PLCCB1 activation. Intra-VTA administration of the highest effective dose of nor-BNI ( $500 \mathrm{ng} / 0.5 \mu \mathrm{l})$ does not produce any behavioral motivational effects in and of itself $(n=8$; right). $B$, Intra-PLC administration of AM251 ( $500 \mathrm{ng} / 0.5 \mu$ l) following intra-VTA administration of the MOR antagonist cyprodime $[50(n=7)$ or $500(n=7) \mathrm{ng} / 0.5 \mu$ l] dose-dependently blocks the ability of intra-PLC CB1 receptor blockade to potentiate sub-reward threshold morphine effects, relative to intra-PLC AM251 alone $(n=8)$. In contrast, intra-VTA administration of the KOR antagonist, nor-BNI ( $500 \mathrm{ng} / 0.5 \mu \mathrm{l} ; n=6)$ fails to reverse the effects of intra-PLC CB1 blockade. Intra-VTA administration of the highest effective dose of cyprodime $(500 \mathrm{ng} / 0.5 \mu \mathrm{l})$ does not produce any behavioral motivational effects in and of itself $(n=8$; right).

remove tonic inhibitory influences of VTA DAergic inputs to the mPFC on cortical neuronal subpopulations (Pistis et al., 2001).

In the context of fear-related learning and memory, considerable evidence implicates a role for intra-mPFC CB1 transmission. Thus, activation of CB1 transmission in the mPFC potentiates normally sub-threshold fear-memory formation behaviorally and associative neuronal conditioning (Laviolette and Grace, 2006). Cannabinoid transmission within the BLA also modulates fear memory processing via modulatory inputs to PLC neurons (Tan et al., 2010). In terms of reward-related learning and memory, $\mathrm{CB} 1$ transmission has been shown to modulate the rewarding properties of opiates, via interactions with mesolimbic circuits. For example, CB1 receptor agonists such as WIN 55,212-2 have been shown to directly excite DA neuron activity within the VTA (French et al., 1997) and potentiate the reward salience of opioids (Caillé and Parsons, 2006). Nevertheless, most previous studies have used systemic administration of cannabinoid agents and little is known related to how direct CB1 signaling within specific cortical regions, such as the PLC, may modulate reward-related signals.
Given previous evidence showing that CB1 agonists can increase subcortical DAegic transmission (French et al., 1997; Pistis et al., 2001, 2002; Cheer et al., 2004), our initial hypothesis was that $\mathrm{CB} 1$ activation would potentiate the reward salience of opiates by directly activating a DA-dependent reward pathway in the VTA. Instead, we observed the opposite effect, with CB1 receptor blockade potentiating opiate-reward salience and CB1 activation instead inducing aversive opiate-related behavioral effects. Nevertheless, given the complexity of CB1-mediated control of neuronal network signaling within cortical regions, several functional explanations are possible. For example, in addition to the well established role of CB1 receptor transmission in inhibiting feedforward, GABAergic inhibitory inputs to principal output neurons (Katona et al., 2001; Freund et al., 2003), CB1 receptors also control presynaptic GLUTergic release in various neural regions, including the hippocampus, BLA, and sensory cortical areas (Domenici et al., 2006). One important source of GLUTergic inputs to the $\mathrm{mPFC}$ arises from the BLA. Indeed, CB1 transmission modulates LTP along the BLA-mPFC pathway (Tan et al., 2010, 2011) and is necessary for the effects of intra-PLC CB1 transmission 
A

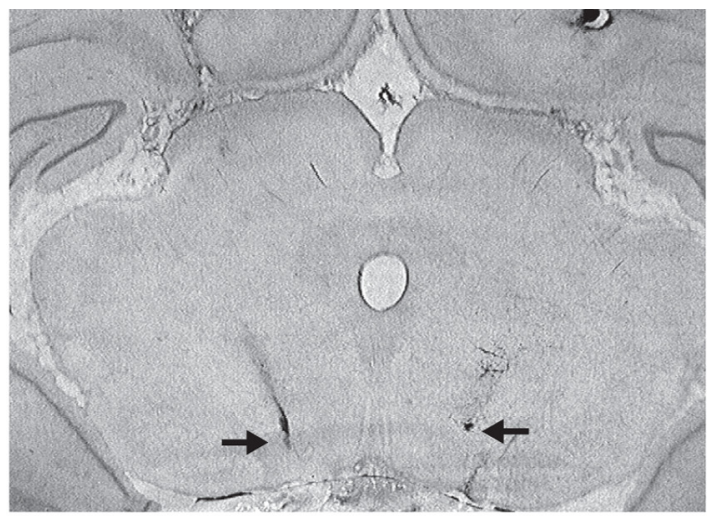

B
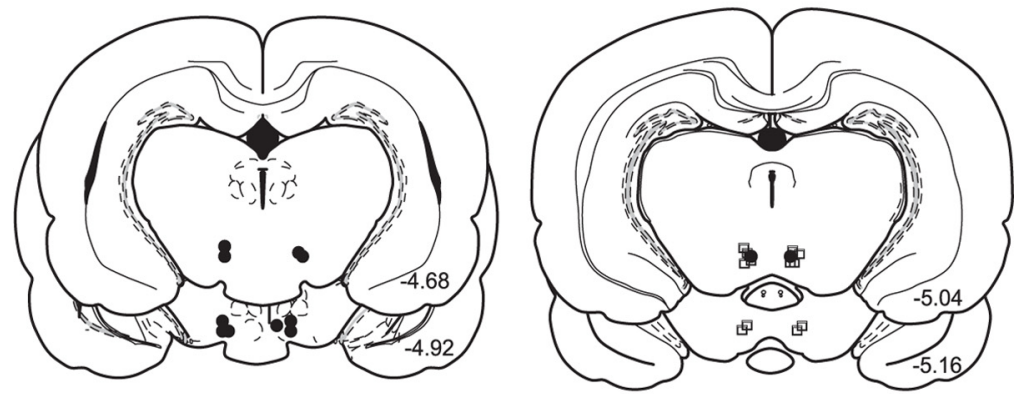

C

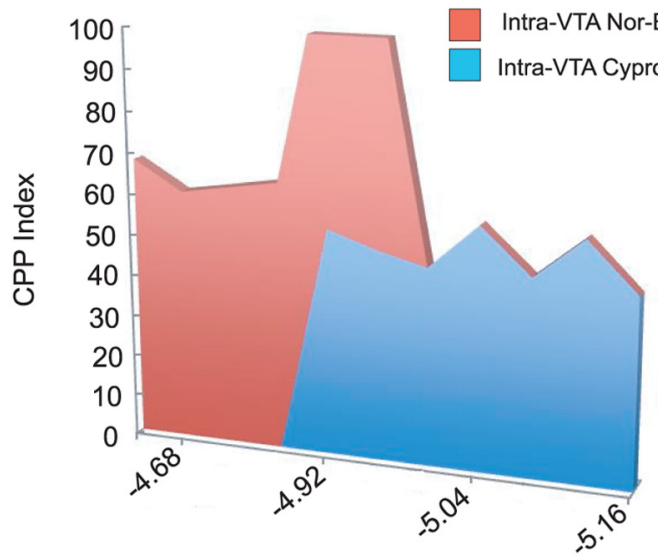

Distance from Bregma (mm)

Figure 7. Histological analysis of intra-VTA microinfusion locations. $A$, Microphotograph showing representative bilateral intra-VTA infusion locations. $B$, Schematic summary of intra-VTA microinjector locations; $=$ intra-VTA nor-BNI $(500 \mathrm{ng} / 0.5 \mu \mathrm{l})$; $\square=$ intra-VTA cyprodime $(500 \mathrm{ng} / 05 \mu \mathrm{l})$. C, Schematic summary showing relative intra-VTA cannulae placement locations relative to behavioral CPP index score (total time in saline environment + total time in morphine environment/total time in morphine environment; de Jaeger et al., 2013) for rats receiving the behaviorally effective doses of either intra-VTA cyprodime or nor-BNI.

on potentiation of fear-related memory and GLUTergic modulation of opiate reward memory formation (Laviolette and Grace, 2006; Bishop et al., 2011). Thus, one possibility is that intra-PLC CB1 activation may inhibit excitatory inputs to PLC output neuron populations, in turn leading to dysregulated or attenuated PLC signaling to downstream DAergic substrates in the VTA.

In vitro studies have demonstrated bidirectional effects of either CB1 activation or blockade on GLUTergic synaptic strength within the mPFC. Thus, CB1 activation suppressesEPSCs, whereas CB1 blockade increases GLUTergic EPSCs recorded in slice (Auclair et al., 2000). Furthermore, DAergic transmission has been shown to modulate synaptic plasticity within the mPFC (Chiu et al., 2010).
Given the bidirectional behavioral effects observed in the present study, an alternative possibility is that CB1 blockade may increase GLUTergic synaptic strength leading to increased PLC output neuron activity to downstream DAergic substrates in the VTA, with $\mathrm{CB} 1$ receptor activation producing the opposite functional effect. Although future studies are required to investigate these possibilities, this model could account for AM251-induced activation of downstream DA signaling and subsequent potentiation of opiate reward salience (by increasing GLUTergic output from the PLC) and by extension, WIN 55,212-2induced inhibition of GLUTergic output from the PLC and a hypothetical inhibition of downstream DAergic transmission. However, such a mechanism cannot account for the observed switch to a robust, DA-dependent behavioral aversion signal. Furthermore, the rewarding effects of opiates can be mediated independently of DA in the previously opiate-naive state (Laviolette et al., 2004).

\section{Cannabinoid modulation of opiate reward and aversion signals is mediated through separate $\mu$-versus $\kappa$-opiate receptor substrates}

Opiates, such as morphine, possess rewarding and aversive stimulus properties. Considerable evidence demonstrates dissociable mechanisms within the VTA for the mediation of MOR versus KORmediated reinforcing versus aversive behavioral effects. Thus, whereas MOR activation is linked to DA neuron activation via indirect inhibition of inhibitory GABAergic VTA neuronal populations (Johnson and North, 1992), KORdependent aversion signals have been linked to direct inhibitory effects on VTA DAergic substrates (Margolis et al., 2003, 2006). Morphine, although showing preferential affinity for the $\mu$-type opiate receptor, also shows affinity for $\delta$ and $\kappa$ receptor subtypes (Yamada et al., 2006), suggesting that multiple opiate receptor pathways may be capable of mediating morphine's behavioral and motivational properties. The aversive effects of systemic morphine have previously been shown to depend on peripheral $\kappa$-receptor substrates (Bechara and van der Kooy, 1987; Bechara et al., 1987). The present results demonstrate that central blockade of $\kappa$ receptors directly within the VTA are capable also of blocking the aversive effects of systemic morphine. Although beyond the scope of the current studies, an interesting question would be whether the ability of intra-PLC cannabinoid activation to induce morphine-aversion effects may be similarly blocked by systemic blockade of $\kappa$ receptors, extrinsic to centrally localized $\boldsymbol{\kappa}$-receptor substrates within the VTA.

In the present study, we observed that both the reward or aversion-related effects of $\mathrm{CB} 1$ receptor modulation were DA- 
dependent. Previous evidence has suggested that KOR-sensitive DA neurons within the VTA preferentially send recurrent projections back to the mPFC. Although the current study used a systemically administered, broad-spectrum DA receptor antagonist, one possibility is that the aversive effects of intra-PLC CB1 activation, mediated through a KOR-sensitive substrate in the VTA, involves a recurrent pathway from the PLC to select DA neurons in the VTA, which then project back to PLC neuronal substrates. Activation of VTA KORs associated with DAergic neuronal subpopulations selectively reduces DA release in the mPFC, but not in the NAc, further suggesting that aversive opiate-related behavioral effects may be mediated through recurrent mPFC-VTA circuitry (Margolis et al., 2006).

Alternatively, the mPFC sends strong GLUTergic projections to the VTA, which are known to synapse upon both DAergic and non-DAergic (presumably GABAergic) neuronal subpopulations and again, these inputs appear to selectively target recurrent DAergic projections back up to the mPFC (Sesack and Carr, 2002). Given the present findings wherein the CB1-mediated switch from opiate reward to aversion was dependent upon both DAergic and KOR-dependent transmission, intra-PLC CB1 activation may selectively activate efferents to the VTA, which act directly upon KOR substrates associated with VTA DAergic neuronal populations, leading to dysregulation and/or attenuation of DA signaling back up to the mPFC. In contrast, the DAdependent, reward potentiating effects of intra-PLC CB1 receptor blockade were mediated through MOR, but independent of KOR signaling within the VTA. This would suggest that inhibition of CB1 transmission within the PLC may indirectly activate DA-dependent reward salience signaling in the VTA via MOR substrates, likely associated with non-DA, GABAergic neuronal subpopulations in the VTA, as suggested by previous reports (Gysling and Wang, 1983; Johnson and North, 1992). Interestingly, MOR-associated DAergic neurons within the VTA have been shown to preferentially project to the BLA (Ford et al., 2006). Although future studies are required to examine these issues, one possibility is that opiate reward signals are amplified through a PLC-VTA-BLA circuit, via MOR-mediated activation of VTA $\rightarrow$ BLA DA projections. Indeed, we have reported previously that direct activation of DA D1 receptor transmission within the BLA can strongly potentiate normally sub-reward threshold morphine conditioning signals (Lintas et al., 2012), suggesting a putative mechanism whereby increased DA input to the BLA may increase opiate-related reward salience, as observed in the present studies. In summary, the present findings add new insights into the role of prefrontal cortical cannabinoid transmission on the modulation of motivationally salient, reward-related memory processing. Furthermore, the present findings suggest that disturbances in CB1 transmission within $\mathrm{mPFC}$ circuits may underlie subcortical DAergic dysregulation linked to neuropsychiatric disorders, such as addiction and schizophrenia.

\section{References}

Akirav I, Fattore L (2011) Cannabinoid CB1 and dopamine D1 receptors partnership in the modulation of emotional neural processing. Front Behav Neurosci 5:67. CrossRef Medline

Auclair N, Otani S, Soubrie P, Crepel F (2000) Cannabinoids modulate synaptic strength and plasticity at glutamatergic synapses of rat prefrontal cortex pyramidal neurons. J Neurophysiol 83:3287-3293. Medline

Bechara A, van der Kooy D (1987) Kappa receptors mediate the peripheral aversive effects of opiates. Pharmacol Biochem Behav 28:227-233. CrossRef Medline

Bechara A, Zito KA, van der Kooy D (1987) Peripheral receptors mediate the aversive conditioning effects of morphine in the rat. Pharmacol Biochem Behav 28:219-225. CrossRef Medline

Bishop SF, Lauzon NM, Bechard M, Gholizadeh S, Laviolette SR
(2011) NMDA receptor hypofunction in the prelimbic cortex increases sensitivity to the rewarding properties of opiates via dopaminergic and amygdalar substrates.Cereb Cortex 21:68-80. CrossRef Medline

Bozarth MA, Wise RA (1981) Intracranial self-administration of morphine into the VTA area in rats. Life Sci 28:551-555. CrossRef Medline

Caillé S, Parsons LH (2006) Cannabinoid modulation of opiate reinforcement through the ventral striatopallidal pathway. Neuropsychopharmacology 31:804-813. CrossRef Medline

Carr DB, Sesack SR (2000a) Projections from the rat prefrontal cortex to the ventral tegmental area: target specificity in the synaptic associations with mesoaccumbens and mesocortical neurons. J Neurosci 20:3864-3873. Medline

Carr DB, Sesack SR (2000b) GABA-containing neurons in the rat ventral tegmental area project to the prefrontal cortex. Synapse 38:114-123. CrossRef Medline

Cheer JF, Wassum KM, Heien ML, Phillips PE, Wightman RM (2004) Cannabinoids enhance subsecond dopamine release in the nucleus accumbens of awake rats. J Neurosci 24:4393-4400. CrossRef Medline

Chiu CQ, Puente N, Grandes P, Castillo PE (2010) Dopaminergic modulation of endocannabinoid-mediated plasticity at GABAergic synapses in the prefrontal cortex. J Neurosci 30:7236-7248. CrossRef Medline

Davis CM, Rice KC, Riley AL (2009) Opiate-agonist induced taste aversion learning in the Fischer 344 and Lewis inbred rat strains: evidence for differential mu opioid receptor activation. Pharmacol Biochem Behav 93:397-405. CrossRef Medline

de Jaeger X, Bishop SF, Ahmad T, Lyons D, Ng GA, Laviolette SR (2013) The effects of AMPA receptor blockade in the prelimbic cortex on systemic and ventral tegmental area opiate reward sensitivity. Psychopharmacology 225:687-695. CrossRef Medline

Diana M, Melis M, Gessa GL (1998) Increase in meso-prefrontal dopaminergic activity after stimulation of CB1 receptors by cannabinoids. Eur J Neurosci 10:2825-2830. CrossRef Medline

Domenici MR, Azad SC, Marsicano G, Schierloh A, Wotjak CT, Dodt HU, Zieglgänsberger W, Lutz B, Rammes G (2006) Cannabinoid receptor type 1 located on presynaptic terminals of principal neurons in the forebrain controls glutamatergic synaptic transmission J Neurosci 26:57945799. CrossRef Medline

Ford CP, Mark GP, Williams JT (2006) Properties and opioid inhibition of mesolimbic dopamine neurons vary according to target location. J Neurosci 26:2788-2797. CrossRef Medline

French ED, Dillon K, Wu X (1997) Cannabinoids excite dopamine neurons in the ventral tegmentum and substantia nigra. Neuroreport 8:649-652. CrossRef Medline

Freund TF, Katona I, Piomelli D (2003) Role of endogenous cannabinoids in synaptic signaling. Physiol Rev 83:1017-1066. CrossRef Medline

Gysling K, Wang RY (1983) Morphine-induced activation of A10 dopamine neurons in the rat. Brain Res 277:119-127. CrossRef Medline

Johnson SW, North RA (1992) Opioids excite dopamine neurons by hyperpolarization of local interneurons. J Neurosci 12:483-488. Medline

Katona I, Rancz EA, Acsady L, Ledent C, Mackie K, Hajos N, Freund TF (2001) Distribution of CB1 cannabinoid receptors in the amygdala and their role in the control of GABAergic transmission. J Neurosci 21:95069518. Medline

Laviolette SR, Grace AA (2006) Cannabinoids potentiate emotional learning plasticity in neurons of the medial prefrontal cortex through basolateral amygdala inputs. J Neurosci 26:6458-6468. CrossRef Medline

Laviolette SR, Gallegos RA, Henriksen SJ, van der Kooy D (2004) Opiate state controls bi-directional reward signaling via GABAA receptors in the ventral tegmental area. Nat Neurosci 7:160-169. CrossRef Medline

Lintas A, Chi N, Lauzon NM, Bishop SF, Sun N, Tan H, Laviolette SR (2012) Inputs from the basolateral amygdala to the nucleus accumbens shell control opiate reward magnitude via differential dopamine D1 or D2 receptor transmission. Eur J Neurosci 35:279-290. CrossRef Medline

Margolis EB, Hjelmstad GO, Bonci A, Fields HL (2003) $\kappa$-Opioid agonists directly inhibit midbrain dopaminergic neurons. J Neurosci 23:99819986. Medline

Margolis EB, Lock H, Chefer VI, Shippenberg TS, Hjelmstad GO, Fields HL (2006) Kappa opioids selectively control dopaminergic neurons projecting to the prefrontal cortex. Proc Natl Acad Sci U S A 103:2938-2942. CrossRef Medline

Paxinos G, Watson C (1986) The rat brain in stereotaxic coordinates. Sydney: Academic. 
Pistis M, Porcu G, Melis M, Diana M, Gessa GL (2001) Effects of cannabinoids on prefrontal neuronal responses to ventral tegmental area stimulation. Eur J Neurosci 14:96-102. CrossRef Medline

Pistis M, Ferraro L, Pira L, Flore G, Tanganelli S, Gessa GL, Devoto P (2002) Delta-9-tetrahydrocannabinol decreases extracellular GABA and increases extracellular glutamate and dopamine levels in the rat prefrontal cortex: an in vivo microdialysis stud. Brain Res 948:155-158. CrossRef Medline

Rodríguez De Fonseca F, Gorriti MA, Bilbao A, Escuredo L, Garcia-Segura ML, Piomelli D, Navarro M (2001) Role of the endogenous cannabinoid system as a modulator of dopamine transmission: implications for Parkinson's disease and schizophrenia. Neurotox Res 3:23-35. CrossRef Medline

Sesack SR, Carr DB (2002) Selective prefrontal cortex inputs to dopamine cells: implications for schizophrenia. Physiol Behav 77:513-517. CrossRef Medline

Shippenberg TS, Elmer GI (1998) The neurobiology of opiate reinforcement. Crit Rev Neurobiol 12:267-303. CrossRef Medline

Sperlágh B, Windisch K, Andó RD, Sylvester Vizi E (2009) Neurochemical evidence that stimulation of CB1 cannabinoid receptors on GABAergic nerve terminals activates the dopaminergic reward system by increasing dopamine release in the rat nucleus accumbens. Neurochem Int 54:452457. CrossRef Medline

Tan H, Lauzon NM, Bishop SF, Bechard MA, Laviolette SR (2010) Integrated cannabinoid $\mathrm{CB} 1$ receptor transmission within the amygdalaprefrontal cortical pathway modulates neuronal plasticity and emotional memory encoding. Cereb Cortex 20:1486-1496. CrossRef Medline

Tan H, Lauzon NM, Bishop SF, Chi N, Bechard M, Laviolette SR (2011) Cannabinoid transmission in the basolateral amygdala modulates fear memory formation via functional inputs to the prelimbic cortex. J Neurosci 31:5300-5312. CrossRef Medline

Tanda G, Pontieri FE, Di Chiara G (1997) Cannabinoid and heroin activation of mesolimbic dopamine transmission by a common mu opioid receptor mechanism. Science 276:2048-2050. CrossRef Medline

Yamada H, Shimoyama N, Sora I, Uhl GR, Fukuda Y, Moriya H, Shimoyama M (2006) Morphine can produce analgesia via spinal kappa opioid receptors in the absence of mu opioid receptors. Brain Res 1083:61-69. CrossRef Medline

Zangen A, Solinas M, Ikemoto S, Goldberg SR, Wise RA (2006) Two brain sites for cannabinoid reward. J Neurosci 26:4901-4907. CrossRef Medline 